\title{
Activity pattern of foraging in the wandering albatross: a marine predator with two modes of prey searching
}

\author{
Henri Weimerskirch ${ }^{1, *}$, Rory P. Wilson ${ }^{2}$, Patrice Lys $^{1}$ \\ Centre d'Etudes Biologiques de Chizé, CNRS, F-79360 Beauvoir, France \\ ${ }^{2}$ Institüt für Meereskunde, Düsternbrooker Weg 20, D-24105 Kiel, Germany
}

\begin{abstract}
The foraging activity of wandering albatrosses Diomedea exulans was studied with simultaneous use of satellite transmitters, activity recorders and loggers measuring the timing of feeding. On average birds spent $60 \%$ of their foraging time in flight, mostly during the day, and $40 \%$ on the water. mainly at night. Birds landed on the water on average 27 times per day. During the day prey were located in flight and caught just after landing. At night prey were caught using a 'sit-and-wait' technique. A mean of 3.8 landings were necessary to catch 1 prey item. Two main foraging behaviours were recognised: (1) birds followed long curvilinear search routes over oceanic waters where they landed on water irregularly and (2) burds concentrated their searching in a defined area and exhibited multiple take-offs and landings, changing flight direction regularly over a short period. This behaviour was used in neritic waters, but also in some specific oceanic sectors. It occurred during the day; at night birds tended to be much less active. Although concentrated searching increases the probability of encountering prey in a patchy environment, the energetic costs associated with such a flight pattern are probably much higher than for long distance moving. The evolution of these 2 contrasting behaviours is discussed in terms of the trade-off between rate of prey capture and energy costs of flight. It is suggested that predators switch from moving to area-concentrated searching after finding prey, and from searching to moving when prey capture is low.
\end{abstract}

KEY WORDS: Squid · Prey distribution - Satellite tracking · Foraging success · Seabird

\section{INTRODUCTION}

The way in which avian predators use the marine environment is generally poorly known, and this is especially the case for pelagic seabirds such as albatrosses that forage for squids far from their breeding grounds. The study of predator behaviour may also enhance our knowledge of prey distribution, especially for pelagic squids whose distribution and biology are poorly known (e.g Cherel \& Weimerskirch 1995). Information on the movements of pelagic seabirds and their activity budgets and energy expenditure is also essential to understanding the relationship between seabirds and the marine environment (Ricklefs 1990)

\footnotetext{
•E-mail: henriw@cebc.cnrs.fr
}

Information on the activity pattern of birds is especially important as the prevalence of a specific activity is likely to be related to its energetic cost, and ultimately because costs of the activities themselves are likely to have a major influence on the evolution of foraging behaviour (Kacelnick \& Houston 1984). This should be particularly true for central place foragers such as albatrosses that forage thousands of kilometres from their nests (Weimerskirch et al. 1993, Weimerskirch \& Robertson 1994). In recent years, much progress has been made in our knowledge of the foraging ecology of volant pelagic seabirds. Initially activity recorders were developed to allow the determination of the proportion of time spent on the water and in flight (Prince \& Francis 1984, Prince \& Morgan 1987). More recently, satellite telemetry (Jouventin \& Weimerskirch 1990) has allowed workers to determine the movements and 
foraging range of large seabirds. The timing of feeding and size of the prey can be determined by the use of stomach temperature recorders (Wilson et al. 1992, 1995a) and, more recently, implanted heart rate loggers have allowed the accurate measurement of energy expenditure on free ranging black-browed albatrosses (Bevan et al. 1995). However these various devices have rarely been used simultaneously, and generally only 1 aspect of the foraging behaviour has been studied (but see Weimerskirch et al. 1994, Bevan et al. 1995)

The aims of this study were to understand how seabirds search for their prey during their foraging trips at sea, what the energetic implications of such behaviour might be and how foraging behaviour is related to the distribution or availability of marine prey. To do this we used newly developed activity recorders (Wilson et al. 1995b) together with satellite tracking transmitters and loggers to indicate the timing of feeding and size of prey of wandering albatrosses breeding on islands in the Indian Ocean.

\section{METHODS}

The study was carried out from Possession Island (46. $\left.25^{\prime} \mathrm{S}, 5^{\circ} 55^{\prime} \mathrm{E}\right)$, Crozet Islands, in February and March 1994. At this time of the year, wandering albatrosses are incubating. Six adult wandering albatrosses were simultaneously fitted with satellite transmitters, activity recorders and stomach temperature sensors. The devices were attached to birds just finishing an incubation shift, after the egg had been left to its partner and before the bird departed from the nest. After 1 foraging bout at sea the devices were recovered from the birds after they had settled on their nests again. Satellite transmitters, Platform Terminal Transmitters (PTT) Toyocom T-2038, weighing between 55 and $80 \mathrm{~g}$, were attached to the back feathers with adhesive tape. Locations were provided by the Argos system (CLS Argos, Toulouse, France). Locations were analysed following Weimerskirch et al. (1992). The activity recorders were External Temperature Loggers (XTL) weighing $35 \mathrm{~g}$ They were attached to the tarsus on plastic bands using adhesive tape. These loggers (version 'Pillbox', Driesen \& Kern GmbH, Am Hasselt 25, D-24576 Bad Bramstedt, Germany) had a 128 kbyte memory which recorded temperature data (using a PT 100 sensor) with 8 bit resolution between 0 and $25^{\circ} \mathrm{C}$. The relative accuracy was good to $0.1^{\circ} \mathrm{C}$ and absolute accuracy to $0.4^{\circ} \mathrm{C}$. Units were powered by $6 \mathrm{~V}$ Lithium batteries and all units were calibrated in a water bath before and after deployment. Temperature was measured every $16 \mathrm{~s}$. The loggers allowed measurement of sea surface temperature when the bird was sitting on the water (Weimerskirch et al, 1995), but also enabled us to assess the bird's activity take-off or landing on the water as well as flight duration and time spent sitting on the surface. Full description of the logger and the analysis of acquired data is given in Wilson et al. (1995a).

Birds were also induced to swallow stomach temperature loggers (Single Unit Channel Processor, SICUP, Driesen \& Kern) weighing $25 \mathrm{~g}$. These SICUPs, also based on the Pillbox logger, were essentially the same as the XTLs except that they measured temperature within the range 20 to $45^{\circ} \mathrm{C}$. Prey ingestion by the albatrosses was indicated by a precipitous temperature drop followed by an approximately exponential rise as the stomach contents were warmed to body temperature (see Wilson et al. 1992, 1995a). The exact time of the sharp temperature drop corresponds closely to the time when prey are actually ingested whereas the integral under the asymptote can be used as a measure of the prey mass ingested (Wilson et al. 1995a). Analysis of feeding activity was conducted using the program FEEDINT (Jensen Software Systems, Am Schutterrain 31,77694 Kehl, Germany). Absolute prey mass calculations are most effective if the SICUPs are calibrated in the birds themselves. Since this was not done, only relative prey masses could be calculated. Full details of the accuracy of mass calculations determined by stomach temperature integrals are given in Wilson et al. (1995a).

The overall weight of instrumentation (transmitter and 2 loggers) carried by each bird was between 115 and $140 \mathrm{~g}$, i.e. 1.2 to $1.5 \%$ of the average body mass of wandering albatrosses during the incubation period. All loggers were set to record data in Universal Time (UT) as were the times of the locations provided by the Argos System. Day-and night-times experienced by birds were adjusted for their latitude and longitude. To calculate night-time we used civil twilight, which occurs when the sun is at an angle of $6^{\circ}$. or more, below the horizon. To determine where the birds alighted on the water from the activity recorders, which give the exact time of alighting, we considered that birds moved at an average speed calculated from the distance moved between 2 satellite fixes divided by the time.

For the analysis, we considered the sample unit to be the foraging day, which comprises the period of daylight with night being the period of darkness following the daytime period. During the study period, i.e. the mid incubation period, the duration of foraging trips did not vary over time (Weimerskirch 1995). Analyses were performed considering the day as an independent variable. Birds' locations were classified as neritic/offshore when occurring over waters of less than than $500 \mathrm{~m}$ depth. Deeper waters were classified as oceanic 


\section{RESULTS}

The 6 birds fitted with each of the 3 devices spent between 4 and $28 \mathrm{~d}$ at sea and all returned to the colony to start a new incubation shift (Table 1). All birds fledged a chick successfully. PTTs and activity recorders were all recovered, but only 1 SICUP was recovered, from Bird 4, with the others being regurgitated at sea. In addition 1 activity recorder failed to work, so we present here the data for 5 birds

\section{Duration of activity pattern}

Activity recorders allowed us to determine the exact time when birds landed and took-off, and therefore to derive the duration of bouts spent in flight (time elapsed between a take-off and the next landing) and on water (time elapsed between landing and the next take-off), either during the night or during the day (Fig. 1). The duration of activity bouts, either in flight or on the sea ranged between $16 \mathrm{~s}$ (minimum recording time) and $11.01 \mathrm{~h}$. The distribution of in-flight bouts was different to that of on-water bouts $\left(\chi^{2}{ }_{5}=478.2, p<\right.$ 0.001 ), with bouts on water being over-represented by short bouts of less than $1 \mathrm{~min}$, whereas bouts in flight were dominated by bouts of 2 to $10 \mathrm{~min}$ (Fig. 2). For each category, there was also a significant difference between the distribution of night bouts and day bouts (in flight $\chi^{2}{ }_{5}=10.92, \mathrm{p}=0.053$, on water $\chi^{2}{ }_{5}=20.0, \mathrm{p}=$ $0.001)$. For bouts on water, long bouts were more frequent at night than in the day, whereas for bouts in flight, long day bouts were more abundant than long night bouts (Fig 2). There was the reverse tendency for short bouts.

Average values of time spent in different activities were very consistent among birds, but differed greatly for the same bird between days. On average, birds spent $60 \%$ of their foraging time in flight, $44 \%$ by day and $16 \%$ by night, and $40 \%$ on water, $17 \%$ by day and $23 \%$ by night (Table 1). Time spent in flight each day did not differ among individuals $\left(F_{4.62}=0.79, \mathrm{p}=\right.$ $0.535)$.

\section{Distribution of landings}

On average, birds landed on the water 27 times per day (Table 1). The number of landings per day varied significantly between individuals $\left(F_{4,62}=5.0, \mathrm{p}=\right.$ 0.0014 ) with 2 birds with short foraging trips landing on water much more often than the other 3 (Table 1), indicating that birds have different activity patterns, probably related to the foraging area or the type of movement or indicating individual specific patterns.

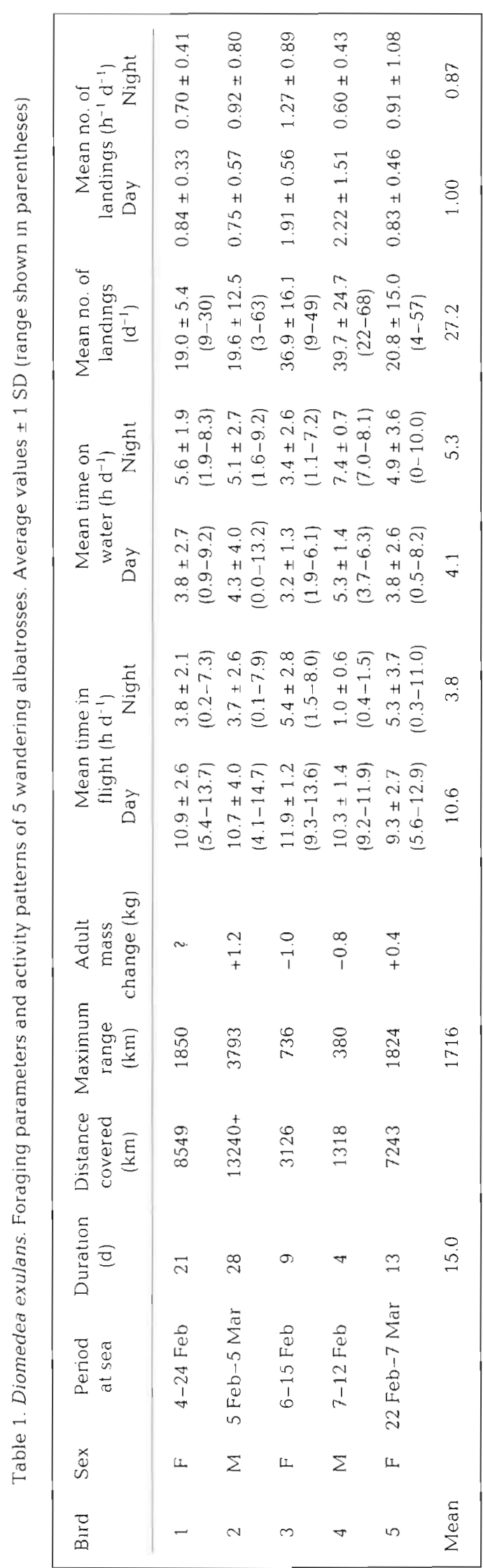




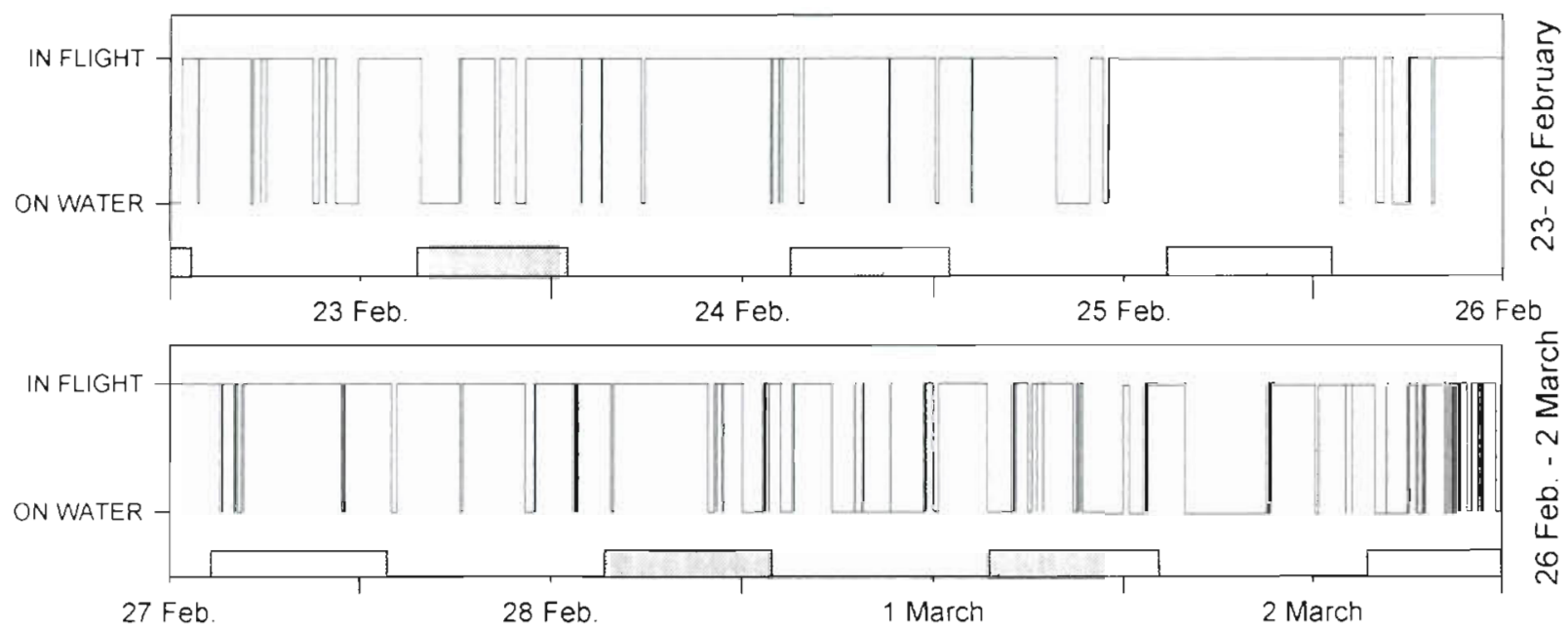

Fig. 1. Distribution of periods spent in flight and on water between 23 February and 2 March 1994 for Bird 5 (wandering albatross Diomedea exulans). Hatched areas indicate periods of darkness. Between 23 and 28 February most time was spent in flight, even at night, whereas from 1 March most time was spent on water
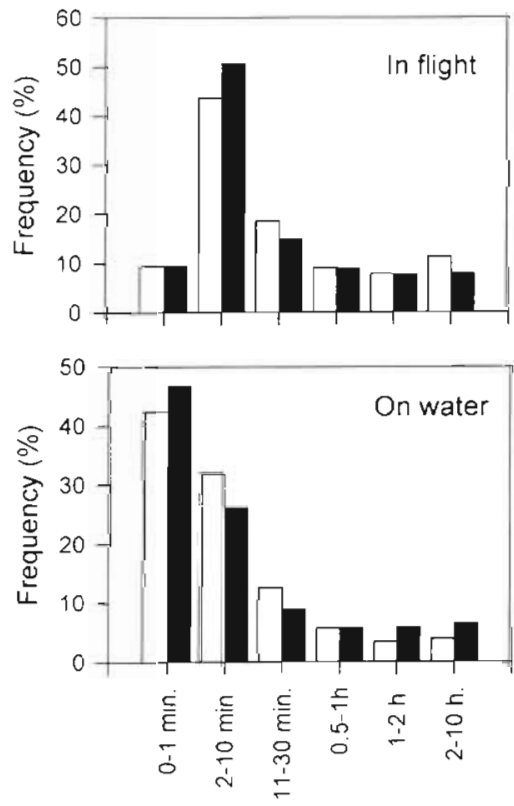

Duration

Fig. 2. Distmbution of bouts in flight and on water during daytume (open bars) and at night (filled bars) for all 5 birds

The number of landings averaged $1.13 \mathrm{~h}^{-1}$, ranging from 0 to 16 (Table 1). Landings occurred at all times over foraging trips but were not evenly distributed, as some periods with frequent landings were followed by periods of continuous flight (Fig. 3). There was no significant difference between the overall number of landings per hour between night and daytime (1.00 0 0.688 and $0.873 \pm 0.764$ respectively, $F_{1.132}=0.99, \mathrm{p}=$
0.32 . The number of landings differed among individuals during the day $\left(F_{4,60}=11.09, p<0.001\right.$; Table 1$)$ but not at night $\left(F_{4,50}=0.88, \mathrm{p}=0.48\right.$; Table 1$)$

\section{Activity pattern in relation to the movement of the bird}

Satellite tracking allowed determination of the movement of the bird and its associated activity pattern, as well as permitting identification of the areas where the activity pattern took place (Figs. 4 \& 5).

Foraging trips were divided into an outbound and a return part. Birds were considered to be returning to the nest when the distance between the bird and the colony started to decrease. Time spent in flight per day was similar for the outbound and the return part of the foraging trip $(15.4 \pm 4.7 \mathrm{~h}, \mathrm{n}=41$ and $14.5 \pm 3.6 \mathrm{~h}, \mathrm{n}=$ 18 respectively, $F_{1,57}=0.471, p=0.495$ ) as was the number of landings per day $(22.0 \pm 13.1$ and $25.7 \pm 12.3$ respectively, $F_{1,5}=0.934, \mathrm{p}=0.337$ )

Short bouts, especially on water, generally occurred serially, corresponding to a series of take-offs and landings (Fig. 1). This behaviour often occurred when birds were not moving on a curvilinear course (e.g Fig 4), but rather changing flight direction regularly (Fig. 5). Conversely, when birds had a curvilinear movement, they generally landed on the water irregularly with long bouts in flight (Figs. 1 \& 4). To test whether differences occur between these 2 types of movement we separated days when birds were moving on a curvilinear line (hereafter termed 'moving') from days when birds changed direction often (this behaviour hereafter called 'searching') Time spent fly- 


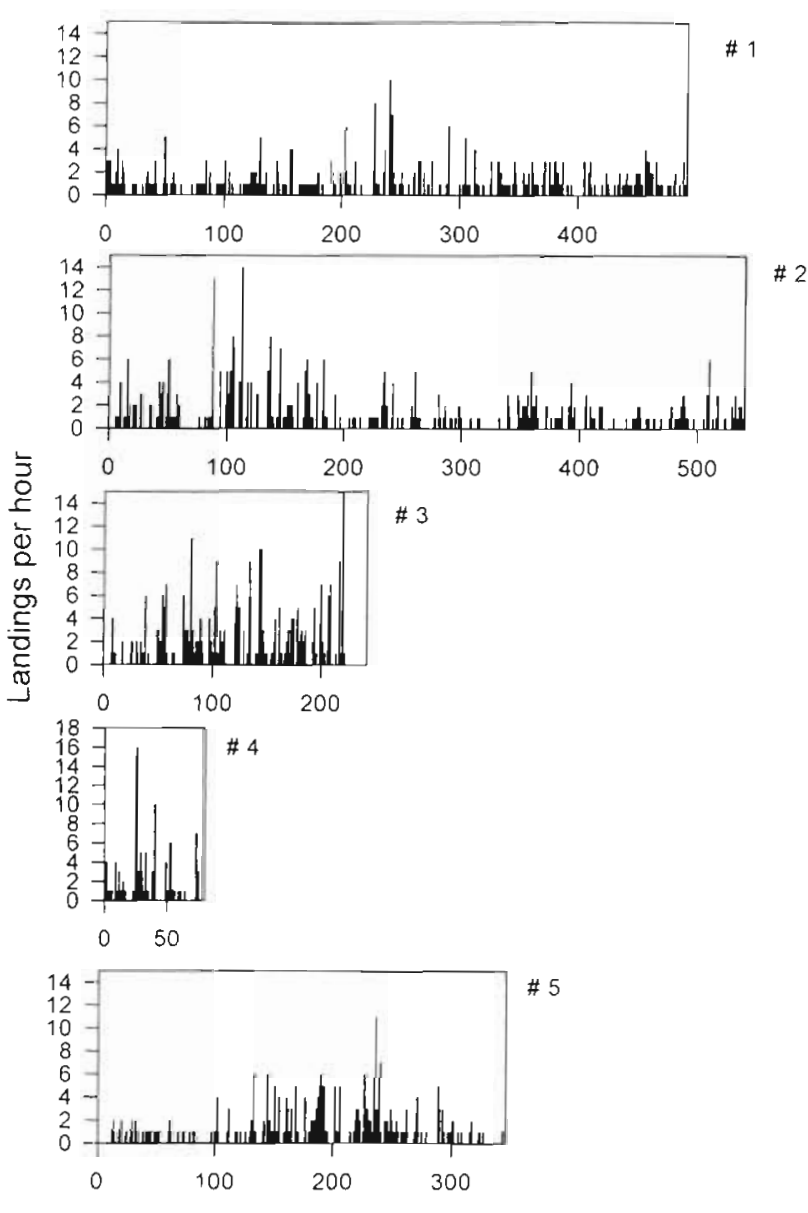

Time since leaving the colony (hours)

Fig. 3. Number of landings occurring per hour over the foraging trips of each albatross

ing per day was not significantly different between 'searching' days and 'moving' days $(17.0 \pm 4.7, \mathrm{n}=11$ and $14.8 \pm 4.3, \mathrm{n}=36$ respectively, $F_{1,45}=2.04, \mathrm{p}=$ 0.160 ) but the number of landings was higher during 'searching' than during 'moving' days $(31.7 \pm 16.4$ landings $\mathrm{d}^{-1}, \mathrm{n}=19$ compared to $21.1 \pm 12.3, \mathrm{n}=36$, $\left.F_{1,53}=7.2, \mathrm{p}=0.0097\right)$. This result was due to differences which occurred during the day $(21.0 \pm 13.6$ landings $\mathrm{d}^{-1}$ compared to $13.0 \pm 8.5, F_{1,53}=7.1, \mathrm{p}=0.0095$ ) rather than at night $(8.1 \pm 7.3$ compared to $10.6 \pm 8.3$, $\left.F_{1,53}=1.29, p=0.261\right)$. During the day, average flight speed, calculated from the distance covered over the daytime, was higher during the curvilinear movements than during the 'searching' movements $[39.5 \pm 11.3 \mathrm{~km}$ $\mathrm{h}^{-1}, \mathrm{n}=36$ and $28.5 \pm 13.3, \mathrm{n}=21, F_{1,55}=10.87, \mathrm{p}=$ $0.0017)$. There was no difference in flight speed during 'moving' and 'searching' at night $(44.0 \pm 27.5$ and 35.6 $\pm 32.2, F_{1,55}=1.06, \mathrm{p}=0.307$ ).

Distance covered per day was not related to the number of landings $(\mathrm{r}=-0.087, \mathrm{n}=58, \mathrm{p}>0.5$ ) but

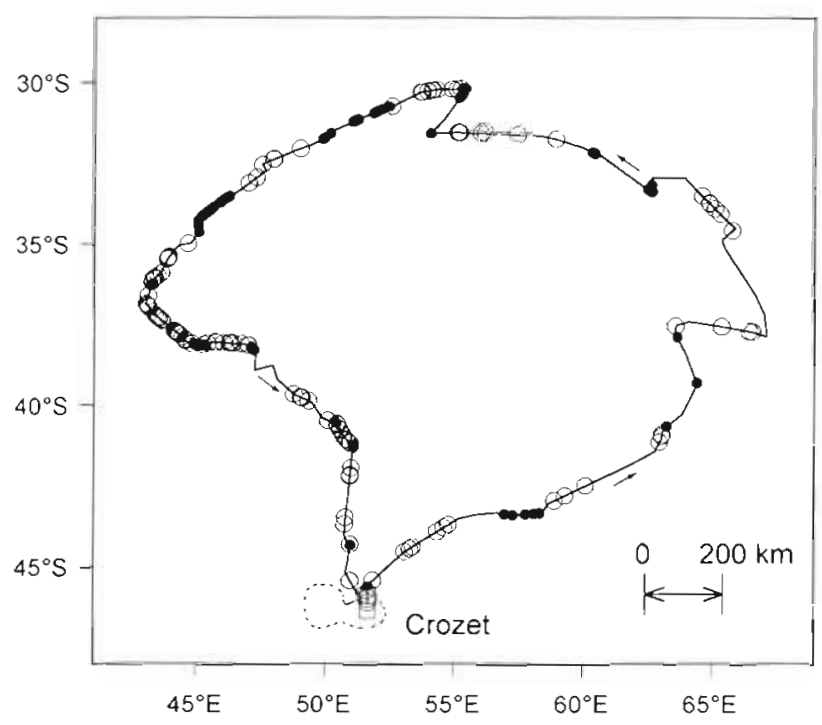

Fig. 4. Foraging movements of Bird 5 indicating the location of all landings on the water during the day $(0)$ and at night (•). The Crozet Islands $(\square)$ and the $500 \mathrm{~m}$ depth line (.....) are also shown

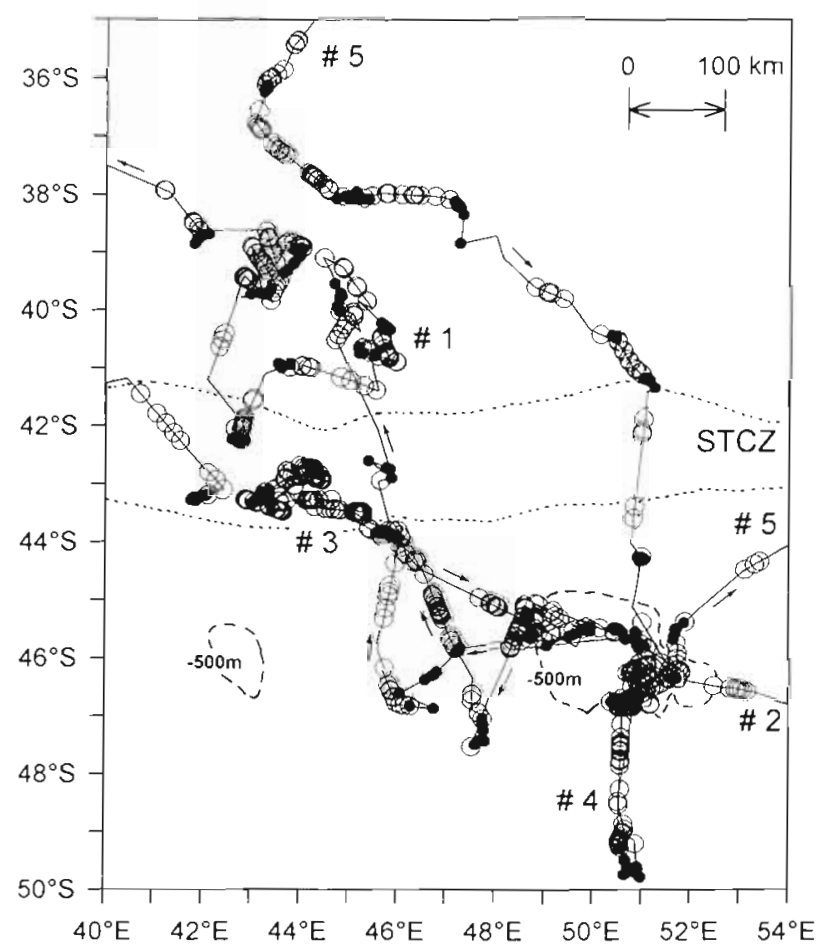

Fig. 5. Foraging movements of Birds 3 and 4 and parts of the foraging movements of Birds 1,2 and 5 indicating the location of all landings on water during the day (O) and at night ( $\bullet$ ). Possession Island is at $46^{\circ} 25^{\prime} \mathrm{S}, 51^{\circ} 55^{\prime} \mathrm{E}$ and the $500 \mathrm{~m}$ depth contour (--) is indicated. Bird 5 shows typical 'moving' behaviour and Bird 1 starts with 'moving' behaviour before engaging in active 'searching' behaviour north of the STCZ (subtropical convergence zone, …......) 
was dependent on the time spent in flight $(r=0.454$, $\mathrm{n}=58, \mathrm{p}<0.001 \mathrm{j}$. To examine whether the distance between the foraging bird early in the morning at dawn and the colony had an influence on the activity pattern, we calculated correlations between this range and distance covered, time spent in flight and number of landings. The only significant relationship was between range and the number of landings during daytime $(r=-0.365, \mathrm{n}=52, \mathrm{p}<0.01)$ indicating that birds tended to land less often when far from the colony.

\section{Activity pattern in relation to the foraging area}

In neritic waters birds tended to exhibit mainly 'searching' behaviour, while in oceanic waters they exhibited both 'searching' and 'moving' Landing on water took place both over offshore/neritic waters and over oceanic waters (deeper than $500 \mathrm{~m}$ ). The rate of landings was not significantly higher in offshore/ neritic waters than in oceanic waters $(29.3 \pm 17.8$ landings $d^{-1}, n=67$ compared to $22.8 \pm 14.0, n=9$ respectively, $F_{1,74}=1.55, \mathrm{p}=0.216$ ). However the rate of land- ings during the day was higher than at night (during the day: $22.0 \pm 16.8, \mathrm{n}=9$ in offshore/neritic waters compared to $13.6 \pm 9.0, n=58$ in oceanic waters, $F_{1,65}=$ 5.1, $\mathrm{p}=0.026$; at night: $7.3 \pm 8.1$ in offshore/neritic waters compared to $8.2 \pm 7.2$ in oceanic waters, $F_{1.65}=$ $0.117, \mathrm{p}=0.73$ ) The time spent in flight was less in neritic/offshore waters than in oceanic waters $(11.1 \pm$ $3.2 \mathrm{~h}, \mathrm{n}=9$ and $15.4 \pm 4.6 \mathrm{~h}, \mathrm{n}=58, F_{1,65}=7.23, \mathrm{p}=$ $0.0091)$. This difference was the result of differences in time spent at night in offshore/neritic waters compared to oceanic waters $(7.0 \pm 1.3, n=9$ compared to $4.7 \pm 2.7$, $\left.\mathrm{n}=58, F_{1,63}=6.3, \mathrm{p}=0.014\right)$ but not from differences during daytime $(5.1 \pm 2.3, \mathrm{n}=9$ and $3.8 \pm 3.0, \mathrm{n}=58$ respectively, $F_{1,65}=1.6, p=0.210$ )

\section{Activity in relation to movement and prey capture}

The data acquired from Bird 4 allowed us to relate precisely the activity pattern to prey capture and to movement and location of the bird (Figs. 6 \& 7). The bird left its nest in the morning on 7 February, moved to the north edge of the peri-insular shelf and spent long periods on the water, when 2 small items (Items 1
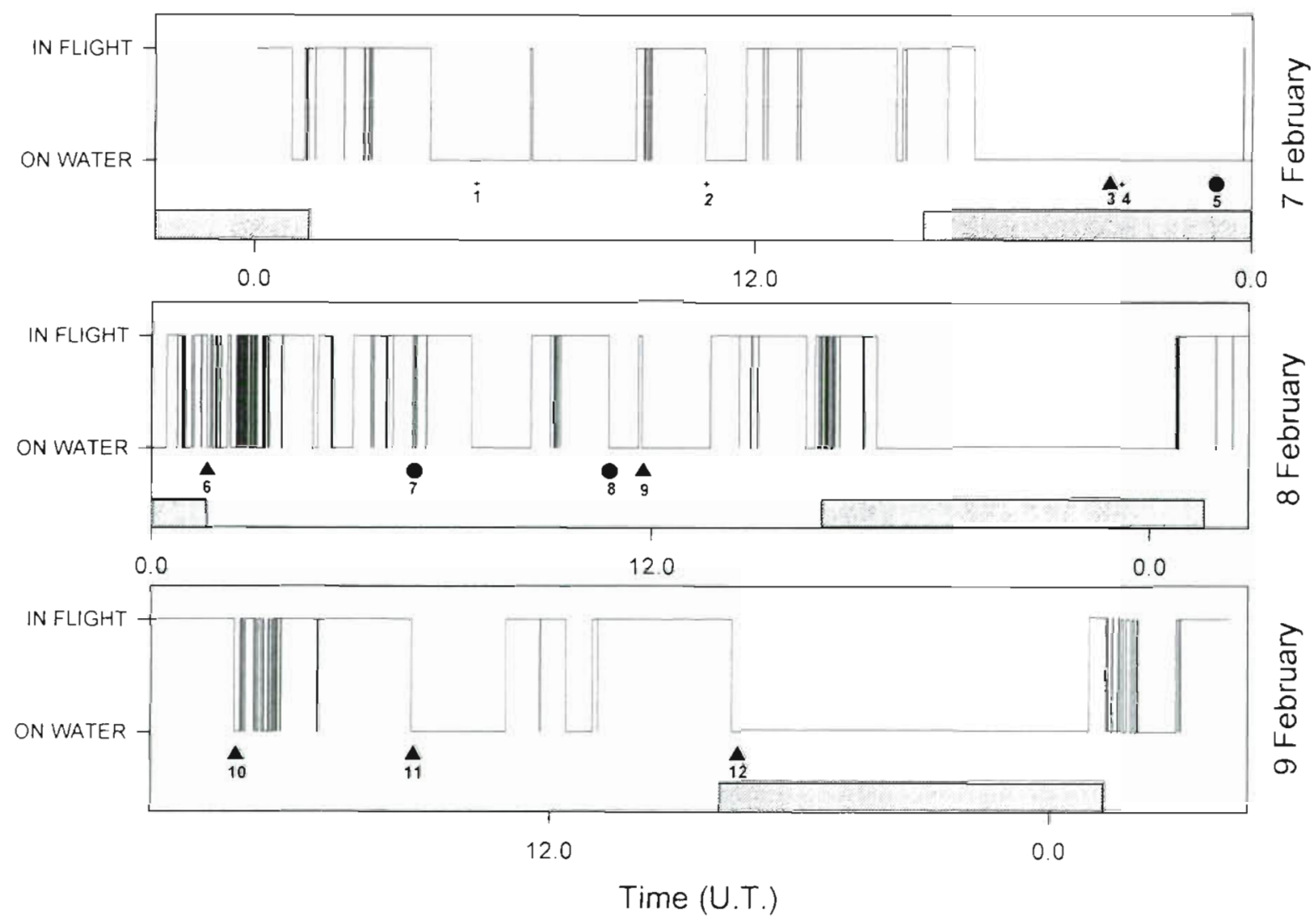

Fig. 6. Distribution of periods spent in flight and on water between 7 and 10 February for Bird 4 . Hatched areas ind.cate periods of darkness. Prey capture is indicated: (+) small items, (†) medium size items and ( $\mathbf{\Delta}$ ) large items 


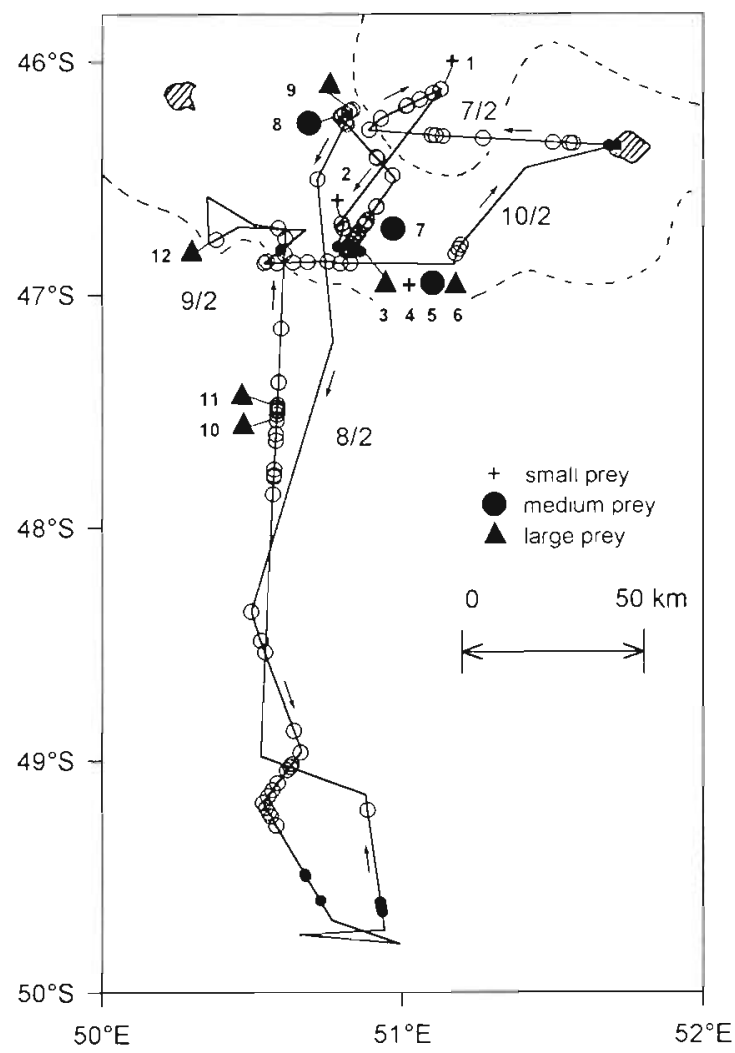

Fig. 7. Foraging movement of Bird 4 indicating the location of all landings on the water during the day $(0)$ and at night $(\bullet)$. The $500 \mathrm{~m}$ depth contour of the peri-insular shelf (-- - -) and the capture of prey items $(+, \mathbf{\Delta})$ are indicated

and 2 in Figs. 6 \& 7) were swallowed. The bird moved to the southern edge of the shelf, where it spent the entire night with only 1 short bout in flight. During this night, 1 large, 1 small and 1 medium prey item (Items 3, 4 and 5 respectively) were swallowed. Before dawn on 8 February the bird began to be very active with numerous successive take-offs and landings in the same area, during which time 1 large prey item (Item 6) was swallowed. The bird then moved to the north, catching en route a medium-sized prey item (Item 7) before reaching the northern edge of the shelf, where it caught 1 medium and 1 large prey (Items 8 and 9). At midday the bird moved south outside the shelf in oceanic waters up to $300 \mathrm{~km}$ south of the colony, where it spent the night on the water. On 9 February the bird moved to the north, spending most time in flight. Three large prey were caught, 2 in oceanic waters (Items 10 and 11) and 1 (Item 12) on the southern edge of the shelf where the bird spent the night without moving. Next morning the bird returned to the colony after multiple take-offs and landings just after dawn.

\section{Influence of the moon phase on night activity}

Moon phase was not related to the number of landings per night ( $\mathrm{r}=-0.0927, \mathrm{n}=68, \mathrm{p}>0.1)$, but was related to the time spent in flight at night $(\mathrm{r}=0.264, \mathrm{n}=$ $68, p<0.05)$ and especially to the distance covered at night $(r=0.588, n=68, p<0.0001)$.

\section{DISCUSSION}

The advance of this study compared to previous studies examining the foraging behaviour of volant seabirds is the integrated use of 3 complementary instruments giving simultaneously the location, activity and time of feeding of the birds. The advantage of the activity recorder used here is that it is the first of this type to record exactly the timing and duration of each activity bout (Wilson et al. 1995b). Data derived from this indicate that the foraging behaviour of birds differs among individuals but also for the same bird between days. Birds may show highly active behaviour with multiple take-offs and landings on the water, or fly for extensive periods without landing (see also Obst et al. 1995 for auklets). Average values for the proportion of time spent in flight in this study are similar to those obtained for the same species at South Georgia (Prince \& Morgan 1987), suggesting that birds could have fairly fixed average activity budgets. For the same period of the breeding cycle, the Crozet birds appear to spend more time on the water at night and less during the day than South Georgia birds (Prince \& Morgan 1987), possibly because of the longer duration of daylight there.

During their foraging trips, wandering albatrosses landed on water on average 27 times per day. However the proportion of flight periods to periods on water were very variable. Some birds flew for up to $11 \mathrm{~h} \mathrm{con-}$ tinuously having periods of flight comprising $91 \%$ of foraging time over $4 \mathrm{~d}$ (Fig. 1, 24 to 27 February). During such periods of intensive flight birds presumably have very little rest or sleep. We assume that time on water is used to sleep, rest, handle prey or to wait for prey to become available for capture. It may also prove necessary for prey digestion to improve flight performance (Guillemette 1994).

\section{Two foraging strategies in wandering albatrosses}

Two main foraging techniques were apparent in this study. The first, 'moving', entails flight over long distances with irregular landing on the water, probably when a potential prey is detected. Birds fly a curvilinear course and do so without landing for long periods. This 
technique is generally used when birds are performing the long looping legs in pelagic waters (see Weimerskirch et al. 1993). The second technique, 'searching', involves more-frequent taking-off and landing on the water. Here the bird repeatedly changes flight direction over a short period. This searching technique is generally used in neritic waters, but also occurs occasionally in oceanic waters. Where this occurred we were unable to relate it to oceanographic features such as frontal zones suggesting that birds did not seem to associate with fronts. It is perhaps noteworthy that Bird 3 moved to the subtropical convergence zone where it engaged in active searching behaviour (Fig. 5).

The 2 types of foraging movements found in wandering albatrosses are similar to the behaviour predicted for animals foraging in heterogeneous environments. Indeed theoretical studies predict that animals should have a linear movement when foraging, but that a high frequency of prey finding should tend to lead to an increased sinuosity of movement and a decreased velocity to increase search effort in the profitable sector (Knoppien \& Reddingius 1985, Benhamou \& Bovet 1989). This switch from one foraging behaviour to the other is particularly apparent in the movement of Bird 1 (Fig. 5). However some birds maintained a curvilinear movement throughout the foraging trip (Fig $4_{i}$ see also Weimerskirch et al. 1993) and despite this caught large number of prey (as suggested by the mass increase of the bird). This suggests that catching prey does not necessarily imply 'searching'. At best, satellite tracking provides 1 location every $2 \mathrm{~h}$ so that only large-scale movement can be resolved. Movements to search for prey presumably also take place on a small scale and are unlikely to be detected if they occur for a short period of time. Nevertheless, theoretical models predict that larger-scale movements with successive changes in flight direction for periods of $1 \mathrm{~d}$ or more are likely to be associated with prey searching (Knoppien \& Reddingius 1985). In wandering albatrosses, these movements take place in neritic waters or in some oceanic sectors. Birds apparently tended not to use the active 'searching' behaviour far from the colonies, as suggested by the inverse relationship between the number of landings and the distance from the colony. This could be related to the incubation trade-off; when time spent at sea rises it increases the probability of catching more prey but it also increases the risk of desertion by the partner incubating the egg, which ultimately limits foraging time (Weimerskirch 1995). Thus, birds foraging far from their nests could be reluctant to spend too much time searching, whereas when they are close to the colony return time is short. Also, theoretically, the yield of foraging trips should increase with the distance from the colony (Lessels \& Stephens 1.983).

\section{Relationship with prey}

Given that the process of 'searching', which involves multiple take-offs and landings or continuous changes in flight direction, is very energetically expensive for albatrosses (see e.g. Bevan et al. 1995), we would expect that the frequency of this behaviour would give clues as to foraging success, with a high incidence being associated with very active foraging and a low incidence being either associated with rest phases or with travelling. In this regard it is interesting to note that, despite fairly substantial inter-individual variation, all birds engaged in periods of very high frequency landings/take-offs (up to a maximum of 10 events $h^{-1}$-nearly 9 times more than the overall mean) at some time during their foraging trips. Such high frequency landings/take-offs may be, for example, due to enhanced prey concentrations, or at least to a greater search effort. The higher number of landings occurring during shorter trips is probably more an indicator of the foraging area or of an individual-specific behaviour rather than of foraging success, since the 2 birds with short trips lost mass. In birds with long looping movements, these increases in landing frequency occurred several times over the foraging trip suggesting that the birds are not commuting to a particular area to forage actively. In this respect, during their long foraging trips wandering albatrosses appear different to other albatross species studied so far, as most species appear to commute to preferred foraging areas (Weimerskirch \& Robertson 1994, Sagar \& Weimerskirch 1996, Weimerskirch et al in press).

Bouts on water shorter than 1 min were very common, indicating that wandering albatrosses repeatedly land on water for very short periods, probably when they have located a potential prey. On average birds land every $31 \mathrm{~km}$. With an average of 27 landings $\mathrm{d}^{-1}$ and 7 items swallowed $d^{-1}$ (Weimerskirch et al. 1994), the catch success is 1 prey per 3.8 landings. During the day, prey are probably located in flight, as prey appears always to be caught just after a landing (except for very small items, Fig. 6). At night prey may be caught after a long period at the surface.

Wandering albatrosses feed mainly on squid (Weimerskirch et al. 1986, 1997, Cooper et al. 1992), whose distribution and ecology are poorly known. Pelagic seabirds such as albatrosses are supposed to rely on prey that has a patchy and unpredictable distribution (Ashmole 1971). The only direct evidence for this is that prey caught by wandering albatrosses tend to be aggregated (Weimerskirch et al. 1994). The results of this study suggest that scavenged squid, the basic prey of wandering albatrosses (Croxall \& Prince 1996), are likely to be clustered, but are unpredictably located in pelagic waters. The long distance foraging 
strategy allows birds to maximise the area searched per unit time. However, once a prey is detected intensive searching would tend to increase the likelihood of encounter (Knoppien \& Reddingius 1985).

\section{Energetic implications}

In neritic and oceanic waters prey caught by wandering albatrosses tend to be aggregated (Weimerskirch et al. 1994). However pelagic waters encompass zones of active searching and zones of long curvilinear movement, i.e. zones of potentially higher prey availability compared to other zones. Why do wandering albatrosses not forage only in neritic waters or in certain pelagic zones close to their breeding sites? Costs of foraging in neritic waters are probably much higher than costs of foraging in looping movements as birds cannot use wind to subsidise the cost of searching behaviour when they regularly change flight direction (Weimerskirch et al. 1993) but also because they take off and land continually (this study), a very expensive activity. Using heart-rate recorders, Bevan et al. (1995) estimated energy expenditure close to the basal metabolic rate (BMR) in black-browed albatrosses moving quickly on a curvilinear route, whereas energy expenditure increased by up to 4 times BMR when birds changed flight direction and decreased velocity, i.e. likely active foraging as suggested by our results. In pelagic waters birds probably moved from one patch to the next. The decision to mave from one patch to the next, i.e. to change from 'searching' behaviour to 'moving' behaviour, is probably related to the rate of prey capture, and quick movement using the wind is probably the most economical flight strategy (Alerstam et al. 1993).

\section{Significance of night activity}

The extent of moonlight appears to have a significant influence on foraging patterns. The fact that moon phase was best related to the distance covered at night, less significantly to time spent in flight and not at all to the number of landings on water suggests that moonlight is used for night-time commuting flight, but not to search for food. At night birds appear to move less over neritic waters than over pelagic waters. A similar tendency exists between days of moving compared to days of searching. This is probably related to the fact that in neritic and oceanic areas 'searching' birds are very active during the day, when they are likely to be searching for food. At night they remain very quiet and often do not move at all, either because they are unable to search for food in the darkness, and therefore rest or sleep, or because they catch prey using a 'sit-and-wait' technique. This technique is probably used by wandering albatrosses, as indicated by Bird 4 catching prey at night after sitting for an extended period on the water (Fig. 6); but, it is probably not the main foraging technique as most prey of wandering albatrosses are caught during the day (Weimerskirch \& Wilson 1992, Weimerskirch et al. 1994). These results suggest that wandering albatrosses could have different feeding techniques for the day and the night, locating prey in flight during the day and employing a sit-and-wait technique at night. Wandering albatrosses are probably mainly scavengers of large squid (Weimerskirch et al. 1986, 1997 , Croxall \& Prince 1994), but prey caught at night could be live prey detected because of movement and not by sight. Small items swallowed by birds could be water intake (Wilson et al. 1995a) especially those occurring shortly after birds return to sea after an incubation fast (authors' pers. obs.).

Acknowledgements. The study received logistical and financial support from 'Institut Français pour la Technologie Polaire' (Program no. 109), from the 'Terres Australes et Antarctiques Françaises' and the 'Deutsche Forschungsgemeinschaft' We thank K. Pütz for help in the field and $M$. Kierspiel for help with the analysis of activity data. Prof. G. L. Hunt and 2 anonymous referees improved the manuscript with numerous comments.

\section{LITERATURE CITED}

Alerstam T, Gudmundsson GA, Larsson B (1993) Flight track and speeds of Antarctic and Atlantic seabirds: radar and optical measurements. Phil Trans R Soc Lond B 340:55-67

Ashmole NP (1971) Seabird ecology and the marine environment. In: Farner DS, King R (eds) Avian biology. Academic Press, New York, p 223-286

Benhamou S, Bovet P (1989) How animals use their environment: a new look at kinesis. Anim Behav 38:375-383

Bevan RM, Butler PJ, Woakes AJ, Prince PA (1995) The energy expenditure of free-ranging black-browed albatrosses. Phil Trans R Soc Lond B 350:119-131

Cherel Y, Weimerskirch H (1995) Seabirds as indicators of marine resources: black-browed albatrosses reeding on ommastrephid squids in Kerguelen waters. Mar Ecol Prog Ser 129:295-300

Cooper J, Henley SR, Klages NTW (1992) The diet of the wandering albatross Diomedea exulans at Marion island. Polar Biol 12:477-484

Croxall JP, Prince PA (1994) Dead or alive, night or day: how do albatrosses catch squid? Antarct Sci 6:155-162

Croxall JP, Prince PA (1996) Cephalopods as prey. 1. Seabirds. Phil Trans R Soc Lond B 351:1023-1043

Guillemette M (1994) Digestive-rate constraint in wintering common eiders (Somateria mollissima): implications for flying capabilities. Auk 111:900-909

Jouventin P. Welmerskirch $H$ (1990) Satellite tracking of wandering albatrosses. Nature 343:746-748

Kacelnick A, Houston AI (1984) Some uffects of energy costs on foraging strategies. Anim Behav 32:609-614 
Knoppien P, Reddingius J (1985) Predators with two modes of searching: a mathematical model. J Theor Biol 114: $273-301$

Lessels CM, Stephens DW (1983) Central place foraging: single prey again. Anim Behav 31:238-243

Obst BS, Russel RW, Hunt GL, Eppley ZA, Harrison NM (1995) Foraging radii and energetics of least auklets (Aethia pusilla) breeding on three Bering Sea islands. Physiol Zool 68:647-672

Prince PA, Francis MA (1984) Activity budgets of foraging grey-headed albatrosses. Condor 86:297-300

Prince PA, Morgan RA (1987) Diet and feeding ecolugr of Procellariiformes. In: Croxall JP (ed) Seabirds: feeding ecology and role in marine ecosystems. Cambndge University Press, Cambridge, p 135-171

Ricklefs RE (1990) Seabırd life histories and the marine environment: some speculations. Colon Waterbirds 13:1-6

Sagar PM, Weimerskirch $H$ (1996) Satellite tracking of southern Buller's albatrosses from the Snares, New Zealand. Condor 98:649-652

Weimerskurch H (1995) Regulation of foraging trips and incubation routine in male and female wandering albatrosses. Oecologia 102:37-43

Weimerskirch $\mathrm{H}$, Cherel $\mathrm{Y}$, Cuenot Chaillet F, Ridoux V (1997) Alternative foraging strategies and resource allocation by male and female wandering albatrosses. Ecology 78

Weimerskirch $H$, Doncaster P, Cuenot Chaillet F (1994) Pelagic seabirds and the marine environment: foraging of wandering albatrosses in relation to the availability and distribution of their prey. Proc R Soc Lond B 255:91-97

Weimerskirch H, Jouventin P, Stahl JC (1986) Comparative

This article was submitted to the editor ecology of the six albatrosses breeding on the Crozet Islands. Ibis 128:195-213

Weimerskirch $\mathrm{H}$, Nougey $T$, Hindermeyer X (in press) Foraging and provisioning strategies of black-browed albatrosses in relation to the requirements of the chick: natural variation and experimental study. Behav Ecol

Weimerskirch H, Robertson G (1994) Satellite tracking of light-mantled sooty albatross. Polar Biol 14:123-126

Weimerskirch H, Salamolard M, Jouventin P (1992) Satellite telemetry of foraging movements in the wandering albatross. In: Priede IG, Swift S (eds) Wildlife telemetry. Ellis Horwood, Chichester, p 185-198

Weimerskirch $H$, Salamolard M, Sarrazın F, Jouventin P (1993) Foraging strategy of wandering albatrosses through the breeding season: a study using satellite telemetry. Auk 110:325-342

Weimerskirch H, Wilson RP (1992) When do wandering albatrosses Diomedea exulans forage? Mar Ecol Prog Ser 86: $297-300$

Weimerskirch H, Wilson RP, Guinet C, Koudil M (1995) The use of seabirds to monitor sea surface temperature and validate satellite remote sensing measures. Mar Ecol Prog Ser 126:299-303

Wilson RP, Cooper J, Plötz J (1992) Can we determine when marine endotherms feed? A case study with seabirds. J Exp Biol 167:267-275

Wilson RP, Pütz K, Grémillet D, Culik BM, Kierspiel M, Regel J, Bost CA, Lage J, Cooper J (1995b) Reliability of stomach temperature changes in determining feeding characteristics of seabirds. J Exp Biol 198:1115-1135

Wilson RP, Weimerskirch H, Lys P (1995a) A device for measuring seabird activity at sea. J Avian Biol 26:172-176

Manuscript first received: October 16, 1996

Revised version accepted: April 16, 1997 